Article

\title{
From Macro to Micro: Impact of Smart Turbine Energy Harvesters (STEH), on Environmental Sustainability and Smart City Automation
}

\author{
Ajibike Eunice Akin-Ponnle ${ }^{1,2, *}$ ) Felisberto Sequeira Pereira ${ }^{2}(\mathbb{C})$ and Raquel Castro Madureira ${ }^{3,4}(\mathbb{C}$ \\ and Nuno Borges Carvalho ${ }^{1,2} \mathbb{D}$ \\ 1 Departamento de Electrónical, Telecomunicações e Informática (DETI), Universidade de Aveiro, \\ Campus Universitário de Santiago, 3810-193 Aveiro, Portugal; nbcarvalho@ua.pt \\ 2 Instituto de Telecommunicações, Universidade de Aveiro, 3810-193 Aveiro, Portugal; felisbertospereira@ua.pt \\ 3 Research Unit on Governance, Competitiveness and Public Policies (GOVCOPP), University of Aveiro, \\ 3810-193 Aveiro, Portugal; rcmadureira@ua.pt \\ 4 Department of Economics, Management, Industrial Engineering and Tourism (DEGEIT), Universidade de \\ Aveiro, 3810-193 Aveiro, Portugal \\ * Correspondence: akinponnle.eunice@ua.pt
}

check for updates

Citation: Akin-Ponnle, A.E.; Pereira, F.S.; Madureira, R.C.; Carvalho, N.B. From Macro to Micro: Impact of Smart Turbine Energy Harvesters (STEH), on

Environmental Sustainability and Smart City Automation. Sustainability 2022, 14, 1887. https://doi.org/ $10.3390 /$ su14031887

Academic Editor: Nallapaneni Manoj Kumar

Received: 9 December 2021

Accepted: 22 January 2022

Published: 7 February 2022

Publisher's Note: MDPI stays neutral with regard to jurisdictional claims in published maps and institutional affiliations.

Copyright: () 2022 by the authors Licensee MDPI, Basel, Switzerland. This article is an open access article distributed under the terms and conditions of the Creative Commons Attribution (CC BY) license (https:// creativecommons.org/licenses/by/ $4.0 /)$.

\begin{abstract}
In the digital transition era of scaling down from macro through micro turbine; to the setting up of Smart Turbine Energy Harvesters (STEH), this paper presents Project Management (PM) principles applicable and best practices to meet the increasing energy demand of digitised technology. The massive deployment of autonomous devices such as those for Internet of Things (IoT), for the support of smart cities, has necessitated more research about their energy demands. With the use of 'waterfall' Project Management Methodology (PMM), turbine grid-connected energy are classified into different categories, and comparative study is made between scaling down of turbine grid from macro to micro, to the economic impact of setting up of STEH. This study concludes by proposing the use of STEH, which is an onsite green energy harvesting scheme that is self-sustaining; ubiquitous; and long lasting; as preferable source to other categories of turbine grid system. Additionally, it is an improvement on energy harvesting $(\mathrm{EH})$ mechanisms using battery; whose replacement and disposal are not economical. STEH is considered economical and time saving with little or no physical and investment risk attached, the Return on Investment (RI) is considered favourable. Also, the energy delivery is sufficient for the requirement of IoT and Wireless Sensor Networks (WSN).
\end{abstract}

Keywords: battery; ecology-sustainability; energy harvesting (EH); Internet of Things (IoT); Project Management (PM); Return on Investment (RI); smart cities; turbine; grid; Wireless Sensor Networks (WSN)

\section{Introduction}

The importance of Wireless Sensor Networks, WSNs, and Internet of Things (IoT) devices to the current developmental stage of technology digitization in terms of improved standard of living in the modern world cannot be played down. This has made WSNs become one major area that energy demands needed to be addressed continually; and considering the rise in the advent of Internet of Things (IoT) devices and other portable devices for smart city, such as: Radio frequency Identification (RFID) Tags, Bluetooth Low Energy (BLE), and so on. [1]. As an instance, the researchers in [2] established that WSNs and/or IoT; and other autonomous devices, usually consume small processing power, and can be used to monitor several parameters such as humidity, temperature, wind speed; which are very important environmental issues in day to day living. Hence, the current trend of digitized technology is also bothering on how energy that is clean and renewable will be supplied to this trending demand of the IoT and other autonomous devices.

Energy harvesting from kinetic energy of wind, or flowing water, have been suitable and popular sources of renewable energy as reported in the literature [3-7]. Turbines are 
devices that convert kinetic energy of wind or water into rotational motion, hence, Turbine Energy Harvesters usually convert energy from the wind or ocean to usable electrical energy forms $[7,8]$. The use of turbines in wind or water as means of generating energy has overtime been a reliable means of renewable energy supply, and they can be used either on macro scale; that is a generating plant that is terminated to a centralised grid [4,9]; or as small scale; such as a turbine that is connected to a mini grid, serving a group of individuals or a community [10].

Meanwhile, Project Management Methodology (PMM) tools are essential in the process of planning towards setting up generating plants, in particular in the occasion of deciding which category of turbine grid-connection is deployable; suitable; and economical in the situation of setting up of IoT nodes or WSNs. PMM are essential tools usually applied in order to enhance the probabilistic realisation of project goals [11].

The main objective of this study is to make comparison among macro, mini, and micro turbines in order to decide which product will be economical, time saving, sustainable, among turbine grid-connected energy sources; compare to supplying clean and renewable energy to IoT devices using Smart Turbine Energy Harvester (STEH).

In addition, a wide range of PMM have been developed by numerous professionals with different techniques to manage projects. In this study, waterfall PMM is adopted being a plan-driven methodology that works based on phase and stage of processes, and it has its history rooted to non-software industries such as construction, where project phases must be accomplished sequentially, since it is unlikely to revisit the previous project phase. Hence, the 'Go/no-go' decisions must be critically accessed before resolutions are taken to proceed to the next phase of the project. Waterfall PMM also uses the Gantt chart as one of its essential tools, which is convenient and easily adaptable for this study [12,13].

Moreover, at power stations, electricity is most often generated by electromechanical operators, primarily driven by heat engines fuelled by chemical combustion or nuclear fission; and also by other renewable means such as the kinetic energy of flowing water and wind [14-17]. Renewable energy sources [16], are beneficial to combat the challenges of global warming and ecological degradation posed by greenhouse gas emission (GHGE), of which the use of fossil fuel to generate energy is a major player as shown in Figure 1.

Modern electrical energy systems usually convert energy from various non-renewable and renewable energy resources to electrical form, thereby making electrical energy to be generated (or produced) by small, medium, and large power plants [18]. Wind and water contribute some proportion in this sense, and they fall under the category of 'other'; representing up to $5 \%$ of total world electricity generation as shown in Figure 2.

Therefore, there is need for the deployment of more modern electrical energy systems that can convert energy from various renewable energy resources to electrical form, moreso, as the trend is for more digitization and smart cities, the current paradigm being smart sensory data from the modern world, for such devices as IoT, WSNs, RFID, etc., of which the Turbine generators are good examples.

With Turbine generators, electrical energy is generated in small, medium, and large power plants. This is determined by the grid sizes, so we talk in terms of macro, mini, and micro grids in this study.

The categorisation of turbine grid-connected energy sources in this paper is made possible by the use of waterfall PMM to make analysis based on the nature of grid that the turbine plants are supplying, whether; they are micro; mini; or macro grids. This is bearing in mind that, electrical energy systems are essentially comprising of; generating stations (or power plants of various conventional and alternate types); transmission networks; distribution networks; and load centres of various capacities [17,19,20]. 


\section{Total U.S. Greenhouse Gas Emissions by Economic Sector in 2018}

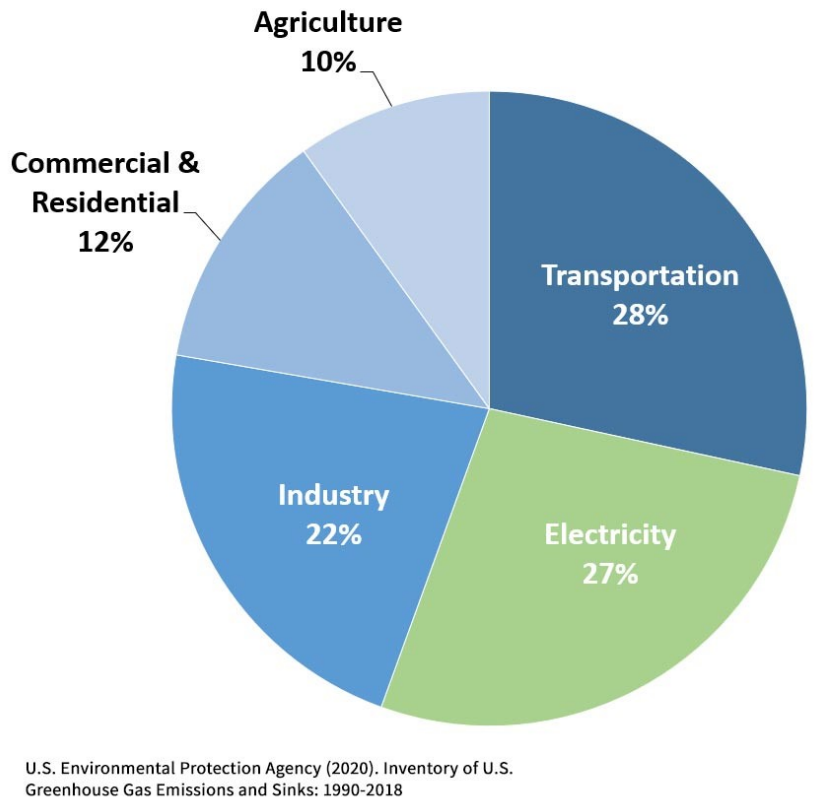

Figure 1. Greenhouse gas emission, source: U.S. Environmental Protection Agency (2020).

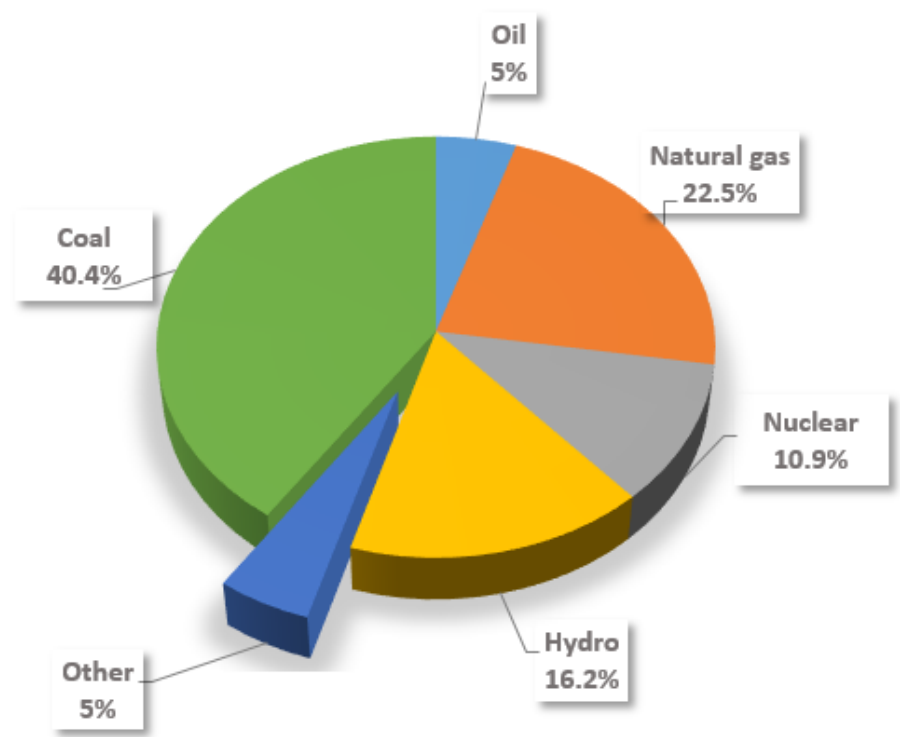

Figure 2. Contributions of green energy sources to world electricity [3].

Meanwhile, the cost of establishing a macro or mini grid in order to scale (or step) down to the very small amount of energy required by these devices; which is usually micro-watts or milli-watts; the man power required; and the time consumed in achieving a scale down from generation through transmission; to distribution to the applicable load centres of IoT nodes, are not a good Return on Investment (RI). This is in comparison with the situations when the energy required to support these devices are in close proximity to, or embedded in the devices by means of energy harvesting techniques [21]. Hence, this study presents the use of smart turbine energy harvesters (STEH), as ideal 'Turbine Harvesters' to supply Internet of Things devices, and their importance as renewable sources 
of energy considering their ecological and environmental friendliness with respect to their capability for sustainability.

In addition, this paper explained that STEH are preferable to some other sources of energy harvesters that require the use of battery or storage devices, for the same economic and ecological reasons. Since there is need that they be replaced and the disposal are toxic to the environment, hence governments at all levels usually expend a lot of money for battery disposal in different parts of the world [22].

Therefore, this paper presents the impact of STEH to the world of IoT and humans; the time saving capabilities; and reduction in cost of harvesting on the site; as well as minimized risk value, rather than scaling down from large turbine plants. All these being an added merits after its usefulness of serving as a green battery-less energy harvester with zero carbon burning. It is also self-sustaining and long lasting, with energy delivery that is ubiquitous. The importance of energy harvesting schemes to the modern world of technology digitization is as shown in Figure 3.

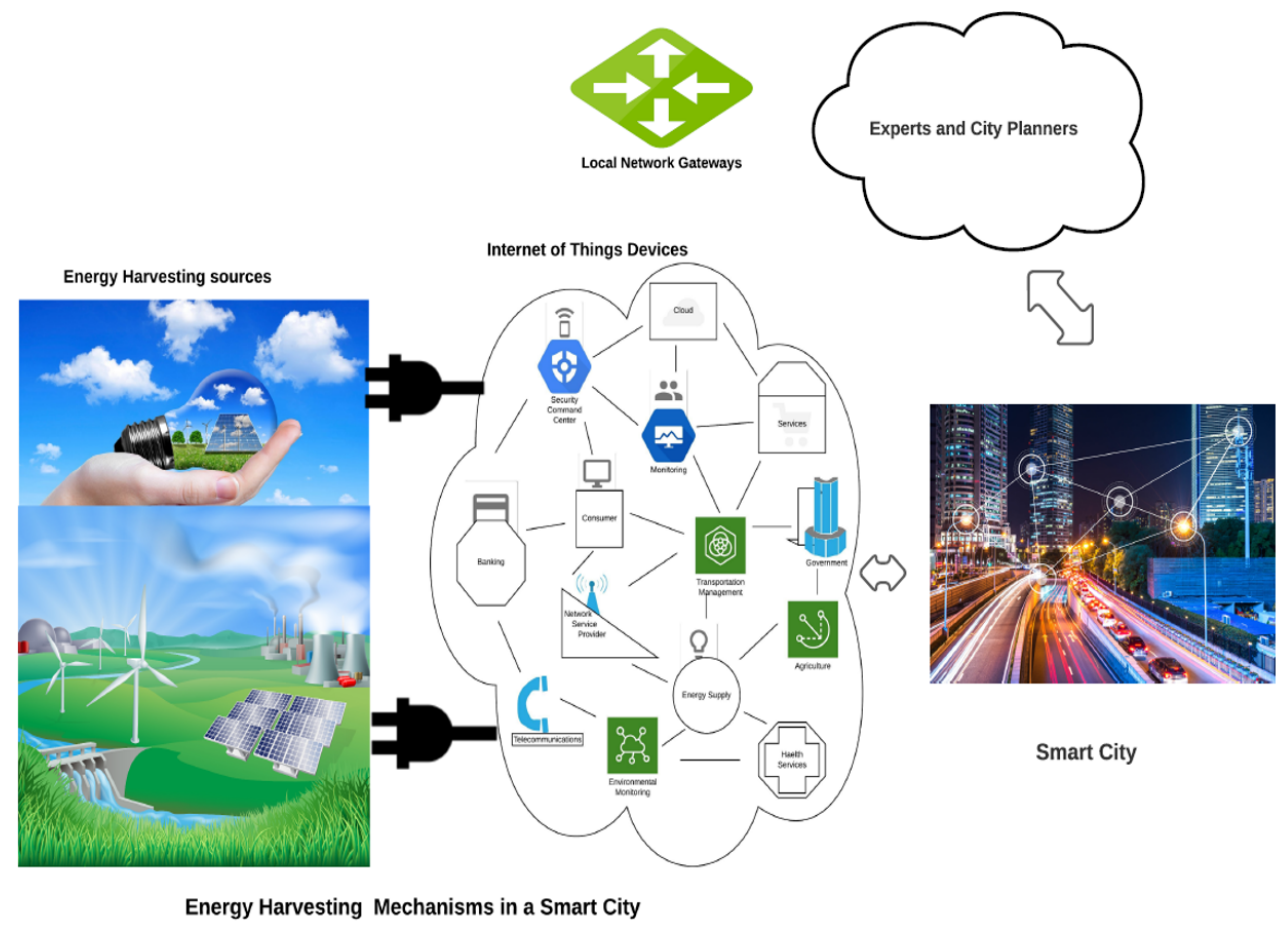

Figure 3. Usefulness of smart energy to IoT and to the smart city.

This paper is organised as follows; first it presents the introduction to this study, this is followed by Section 2; that explains the state of the art of turbine generators and harvesters in sustainable developments goals and in combating global warming related challenges. Here, the importance of wind or water sources of electrical renewable energy are explained. Then, the paper looks into examples of macro, mini or micro grids supplied by turbine generators either from wind or water sources as reported in literature; considering the essential requirements in setting up these types of energy grids.

The Section 3 presents the waterfall Project Management Methodology (PMM), and makes the comparative analysis of supplying energy to autonomous devices among turbine categories using a macro-to-micro source; with supplying the devices directly using STEH.

In the result and discussion sections, which are Sections 4 and 5, results are analysed, then, this paper further elucidated on the need to adopt clean and renewable energy consumption over other sources of energy in order to protect the environment from pollution and for ecological preservation and sustainability. However, in doing this, it is argued that conscious efforts must also be made to avoid; incurring undue cost of producing energy, the time consumed, and most importantly energy wastage must be reduced to the barest 
minimum. Additionally, in reducing cost of labour, it is important that manpower usage is not badly affected in a manner that will lead to economic meltdown. Hence, the need to deploy the toolkit of Project Management Methodology (PMM), such as waterfall PMM to project how to generate or harvest energy based on the capacity of load required. Powering loads such as IoT or WSNs, we propose that using a STEH may be just enough for the purposes of cost saving, and time management. This comparative studies is carried out using waterfall Project Management Methodology.

Additionally, this study presents the advantages of using the STEH over other types of energy harvesters that require the use of battery as storage devices.

The final section, which is Section 6, is the concluding aspect, that rounded up the insights given by this research.

\section{Literature Review of Digitised Technology and Project Management for Turbine Energy Sustainable Goals}

The effect of trending technology digitisation has necessitated the massive deployment of miniaturised and autonomous devices for the purposes of smart city integration, and so the resulting increase in energy demand to power them cannot be underplayed. The paradigm is smart energy from renewable sources, and grid connected turbine energy harvesting is a reliable choice to combat carbon burning from fossil fuel and greenhouse gas emission (GHGE) [23-27].

Meanwhile, there is need to scale down turbine grid technology since there are different sizes of turbine grid capacity; these are classified as macro, mini, and micro in this study. This is achieved by considering the essential requirements adopted in setting up a turbine grid such as; the equipment or facilities, the land purchase, construction (which involves site clearance), development cost, insurance, etc. These factors are important components of Project Management Methodology (PMM) in this paper, and they are determinants of the economic value and the Return on Investment (RI), of any turbine grid; either wind or water. These requirements by way of categorization are aligned with PM processes of initiation; planning; execution, maintenance, monitoring and control, in order to be able to apply PMM for our classification.

In this research, the use of PMM tool from the point of view of Project Manager (PM) is employed, and the focus of this paper is on how renewable electrical energy, particularly turbine generated energy that is connected to the grid, might be distributed to low power consuming autonomous devices, especially the Internet of Things (IoT) devices, and Wireless Sensor Networks (WSN). Much emphases are laid on proposal of how to supply green energy to these devices using wind or water turbines for the purposes of ecological sustainability and environmental protection using PMM.

However, it is important to note that the energy demand of digitized technology or the deployed autonomous devices, though there has been an increased demand, is not of the same capacity in terms of quantity as those for bulk/macro energy consumption. Hence, there will always be the need to carefully project in order not to incur more cost in the process of trying to scale down (that is step down) capacity as the case may be, from macro to micro during generation, through transmission; to distribution; and finally to supply IoT and other related devices.

This section considers the state of the art of turbine generators for wind and water, with examples of what researchers have reported in terms of requirement in literature, while considering the output capacities that can be categorised for the different capacities classified as macro, mini, and micro turbines.

\subsection{Waterfall Project Management Methodology}

Waterfall Project Management Methodology (PMM) usually simplifies projects by using sequential and linear processes, it normally consists of disconnected phases, and one phase will not begin until the completion of the previous. It emanated from non-software industries, and one of its prominent toolkits is the Gantt chart or timeline [13]. Some of 
the requirements of waterfall PPM are; requirement gathering/documentation, system design, Implementation, testing, deployment, and maintenance. These toolkits can be easily incorporated into this research in the process of forecast about the requirements for the best turbine that is suitable for IoT and WSNs energy supply as discussed in Section 2.2.

Many researchers have at one time or the other adopted waterfall PMM to forecast about their Project Management at different times in literature. In [12], W.V. Casteren made a comparison between the waterfall PMM and agile model, where he described waterfall as a model with a plan driven approach having agile methodology as its natural counterpart that uses an adaptive approach.

The advent of waterfall model was traced back to NATO historical conference in the 1960s, where there arose the need for Software Development Models (SDMs) for projects. This opened the era of development of project methodologies, which made teams to create their own plans for the software systems creation methodically. The founding father of SDM can be said to be Dr. Winston Royce [12,28], who wrote an article on how to manage large software developments, and described the fundamentals of SDM in an intermediate phase which forms a SD sequence, as shown in Figure 4.

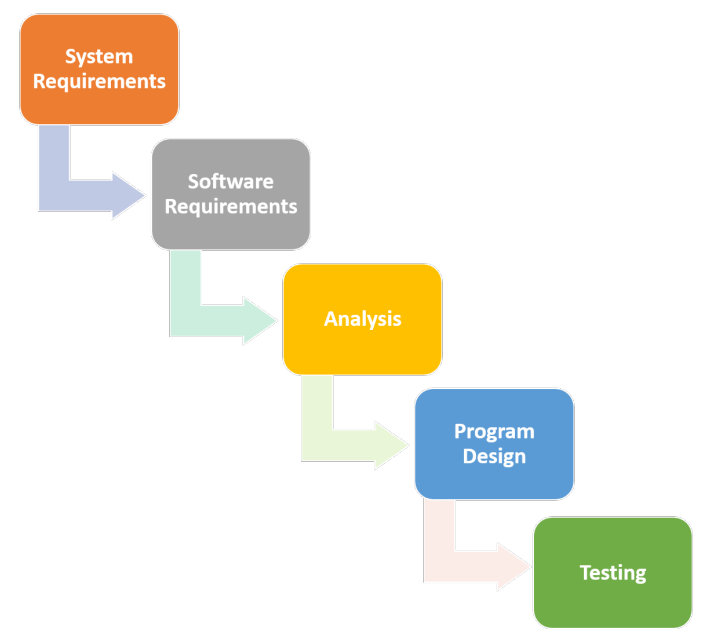

Figure 4. Waterfall Project Management adapted from [12].

However, Bell and Thayer in [28] further named this model 'waterfall' due to the staircase manner of sequential project phases.

\subsection{Turbine Energy Generators for Wind and Water}

Generating stations convert the energy from primary form as available in nature to secondary form as used by consumers, for example in the form of lighting, heat, steam, etc. Hence, as electrical power plants are used all over the world for energy conversion from primary to secondary forms, the energy converted into electrical forms are transmitted and distributed in electrical forms and supplied to users in the same electrical form, but at varying capacities $[19,20]$. The utilization devices convert electrical energy into required form for ultimate consumption such as heating, melting, lighting, transport, driving, entertainment, communication, air-conditioning, electronic equipment, etc. This is usually possible by further scaling down the output energy received at load point by means of step-down transformers and energy converters of various forms, as shown in Figure 5. The details of this aspect are outside the scope of this study. 


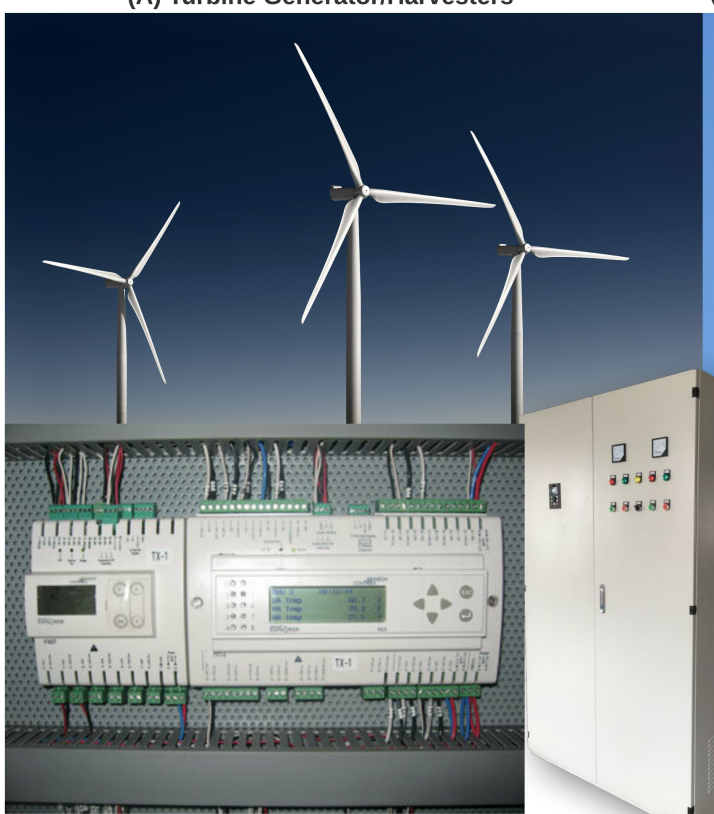

(C) Energy Inverter Controls
(A) Turbine Generator/Harvesters

(B) Turbine Grid Connected Distribution

From Macro through Micro Turbine to Digitised Technology

Figure 5. From macro through micro turbine to digitization.

The intention of most renewable electrical power system supplies is to provide adequate electrical energy to all their consumers at all times and over vast geographical areas; without harming the ecology and environment. This is planned at the lowest possible cost with high reliability, service continuity, and at specified voltages and frequency waveforms $[8,15,16]$.

The use of turbines in wind or water as means of generating energy fall among the fore-going examples, and it serves as a reliable means of renewable energy sources for macro, mini or micro energy generation [3,9].

However, the cost of establishing a macro or mini grid turbine in order to scale down to the small amount of energy required by these devices; which is usually micro-watts or milli-watt; the man power required; and the time consumed in achieving a scale down from generation through transmission; to distribution to the applicable load centres; which in this case are IoT nodes or WSN, may not be a good Return on Investment (RI), as it is going to be unveiled by PMM in the next section. This is in comparison with the situations when the energy required to support these devices is in close proximity, or embedded in the devices by means of energy harvesting techniques such as smart turbine energy harvester $(\mathrm{STEH})$, that is presented in this paper.

\subsection{Requirements for Setting Up Turbine Grid-Connected Energy Source}

Some of the essential requirements of setting up a wind turbine are as highlighted in this section:

- Good site or location: owing to the fact that some sites are windier than others, a good land or location for the turbine installation must be decided. The amount of energy realisable is usually proportional to the cube of the wind speed. An average of $7 \mathrm{~m} / \mathrm{s}$ wind speed is considered sufficient, and most of the time, top-of-hill locations are preferable for optimal exposure of macro or mini turbines to strong winds [29].

- Good grid connection: a suitable three-phase electrical connection is required to be connected to; an $11 \mathrm{KV}$ substation or transformer is required for a mini grid turbine while up to $33 \mathrm{KV}$ power lines grid connection might be required by a macro/bulk turbine farm. 
- Good and sufficient noise separation: the neighbourhood of the turbine plant must be well separated from noise pollution; there are stringent rules to the permissible noise level depending on the category of turbine either macro or mini.

- Good site access: turbines could be very large or heavy, especially those for macro grid plants, hence there is need to make choices of site to be accessible to good roads and tracks with strong bridges for the delivery of large constituents parts of the turbine and other equipment.

- Consideration for environmental and landscape designation: peat bog and bird strikes should be avoided. Those sites with good landscape may not be able to obtain planning consent, since they are useful as natural beauty or park areas.

Hence, important issues for proper consideration are: land purchase, equipment, construction, site clearance, development, connections to the grid, making insurance, etc. These are dependent on the category of turbine, with the most involving requirements being macro turbine grid connected energy source. This is as described in the following highlights, where this paper points out some state of the art in the literature about the categories of turbine from macro- to- micro.

\subsection{Macro/Bulk Turbine Energy Generator}

Researchers in [4] reported that up to 10 million megawatts of energy can be realised from the aerodynamic blades of a turbine in converting its rotating mechanical power through wind energy. In this scenario, the land requirement to make the wind farm can be up to few hectares, since the wind turbines needed to be 5-rotor diameters apart to avoid turbulence. Hence, a $500 \mathrm{KW}$ turbine will require about $250 \mathrm{~m}$ apart; while up to $410 \mathrm{~m}$ will be required for a $2.5 \mathrm{MW}$ turbine. This forms the basis for which the sizes of macro or mini turbine farm are decided with respect to land requirement.

In [30], research showed that power system planners need a careful understanding in studying the impact of turbine inter-connectivity in a large farm, while they made effort to develop an equivalent collector for power system planning studies, arguing that there could be a single farm containing hundreds of megawatt-size turbines that are interconnected. The collector systems will also address issues of energy losses and voltage drops during transmission system integration. Here, a current utility-scale wind turbine is said to range from 1.5 MW to $5 \mathrm{MW}$ per turbine. This is huge; a macro/bulk turbine, as opposed to a few milli-watts required to power an IoT.

However in terms of turbine market PM projections, macro turbine has contributed up to $5 \%$ to the central grid, with a global capacity of over 17,600 MW, of which the United States alone can account for 1800 MW of these installations as of the year 2000 [31]. The European Wind Energy Association (EWEA) has increased the estimated wind installations since 1993, and over $3000 \mathrm{MW}$ was installed in 1999, bringing the total installed capacity to $9500 \mathrm{MW}$ in that year. Hence the target of $150 \mathrm{GW}$ by 2020 is possible with the help of European Commission according to studies. Researchers also believe that cost of large wind power plants has declined at good wind sites to around $\$ 0.05 \mathrm{k} / \mathrm{Wh}$, and the combined global sales is up to $\$ 4-5$ billion annually.

Meanwhile, turbine energy generation can be classified into two processes; the first being aerodynamic conversion of kinetic energy of moving air from turbine rotor into electrical energy [32], and the second process involves electro-mechanical energy conversion by using a generator, which is later transmitted to electrical grid. The sizes of turbine plants are determined by the grid size whether large/bulk or macro turbine.

\subsection{Mini Turbine Energy Grid}

Mini turbine grid sources are the small-scale generation of electric power by individuals, small businesses and communities to meet their private energy needs, as alternatives or supplements to centralized grid-connected power [10]. Although this may be motivated by practical considerations, such as unreliable grid power or long distance from the electrical grid, the term is mainly used currently for environmentally conscious approaches that 
aspire to zero or low-carbon footprints. Some are also referred to as smart grid sources, the size of which can be around that of a football field, and between $3 \mathrm{KW}$ and $3 \mathrm{MW}$ of energy may be realised in this case [33-35].

\subsection{Micro Turbine Energy Generator}

Micro Turbine Power Generation describes the work that researchers are currently doing to develop very small electric generators or devices to convert kinetic energy from wind or water to electricity, thereby offering the promise of power sources for portable and autonomous electronic devices. Most micro turbine usually aim at generating energy to supply WSNs and autonomous devices [36,37].

In [36], studies about micro turbine with an overall volume below $300 \mathrm{~cm}^{3}$, meant to power outdoor small size embedded system was researched, the diameter of the turbine in this case is $6.3 \mathrm{~cm}$, and can generate up to 10 milli-Watt at wind speed of $16 \mathrm{~km} / \mathrm{h}$. In the same vein, the application of bio-composite fibre materials to make micro wind turbines in Structural Health Monitoring (SHM) was researched in [37]. This can be a perfect substitute to batteries in implantable and wearable devices.

\subsection{Smart Turbine Energy Harvester (STEH)}

The requirements for setting up turbine grid-connected energy sources were highlighted in Section 2.3, and among the leading factors is a good wind site, since the amount of energy realisable is a function of wind speed [29]. In a similar manner, this is informed of the location for experimental set-up of STEH in this study; though not grid-connected, but this can apply to any location or site that meets up with the related parameters as discussed in this section. Wind energy is inexhaustibly available in Aveiro; with an average speed of $16 \mathrm{~km} / \mathrm{h}$; which is at the same time a city endowed with surrounding waters of the beach, with Aveiro being located on latitude $40^{\circ} 38^{\prime} 39^{\prime \prime} \mathrm{N}$, longitude $8^{\circ} 38^{\prime} 43^{\prime \prime} \mathrm{W}$, the city has sufficient wind throughout the year, (Source: weather.com). Hence, this city, as an example of smart city, is a suitable location to experiment with Smart Turbine Wind Energy Harvester, with the device for Smart Wind Turbine Energy Harvester (SWDT-EH) being a passive material of the home chimneys in Portugal. However, the STEH can be set up in any location that satisfies some factors discussed in Section 2.3 that are applicable, since wind or water is general and available everywhere. The device for STEH in this study is usually used to prevent birds from entering into the chimney, and it is available on most roof-tops of Portuguese homes. In [21], it is stated that there is a desire to harness energy from every available ambient energy in the environment and in close proximity to the load nodes. Hence, the interest in converting a chimney device to a table top Smart turbine of 18 vertical blades [38], is born out of the fact that ambient energy is wasting away from the continuous aerodynamic activity of this device which is constantly spinning without connecting any active device. This basically works using the aerodynamic principle [39] to convert wind energy to electrical energy in order to supply energy to IoT, WSNs, or autonomous devices. The counterpart Smart Turbine Water Harvester (SWRT-EH) is born out of the passion that all existing turbine generators from macro to mini grids require either the use of sophisticated accessories before energy could be delivered at load point, and in most cases the use of battery is in place. However, SWRT-EH is a smart water turbine energy harvester that is built together with the device meant to service underwater applications and so does not require the use of battery. It adopts the hydrodynamic principle [40] to convert energy from ocean torrents to electrical energy for the purposes of powering underwater sensors. The SWDT-EH and the SWRT-EH are therefore referred to as STEH in this paper, and experiments reveal that they are suitable to power autonomous sensors and devices of low input voltage in the range of $220 \mathrm{mV}$ to $1.7 \mathrm{~V}$, with up to 13.69 milli-watt realisable from the set-up. 


\section{Methodology}

The comparative analysis of different categories of turbine grid-connected harvesters: from macro to micro, with STEH is carried out using watefall PMM.

Waterfall PMM is an old model of Project Management with the advantages of being a plan-driven model.

Using waterfall PPM in this research enables easy integration of the requirements of setting up a turbine harvester or turbine generating plant, to Project Management processes. Such processes, in terms of initiation, planning, execution, maintenance, controlling and up to closing of the project, are aligned with the requirements for setting up turbine energy sources discussed in Section 2.2. These requirement include, but are not limited to; project proposal, land purchase, equipment acquisition, construction and site clearance, development and energy generation, transmission, distribution, termination to load, etc.

\section{Waterfall PMM Using Gantt Chart with Requirement Processes}

This study adopts the methodology of waterfall Project Management to analyse and describe the basic requirements of setting up of turbine grid-connected energy as explained by the itemised Gantt charts in this section:

- Macro Turbine Grid-Connected Energy Source;

- Mini Turbine Grid-Connected Energy Source;

- Micro Turbine Energy Harvester (With Battery);

- $\quad$ Smart Turbine Energy Harvester (Battery-Less STEH).

In relating the requirements of PMM toolkits in Table 1 to the waterfall Gantt charts in Figures 6-9, the project processes of one calendar year are subdivided into 52 weeks, remembering the waterfall PMM rule that says one process stage must completed before proceeding to the next. Hence, in comparison, not all types of turbine categories will arrive at the execution phase at the same time. The STEH PMM will arrive very early after about 6 weeks, as shown in Figure 9; while the micro turbine PMM will begin its execution at the same time with STEH, but will last in this phase for another 2 weeks more than STEH. This is as shown in Figure 8. The waterfall PMM for a macro turbine grid-connected plant will stay long at initiation and planning phase more than all the four categories of turbine energy source discussed in this study. This is as indicated by the Gantt chart of Figure 6 . The waterfall for the mini turbine in Figure 7 will begin execution after about 20 weeks of initiation and planning, and will commence execution for another 14 weeks before the final PM phase. Whereas, there will be a short period of management and PM phases for macro PMM, as a result of tarring longer at execution for 20 weeks. This is an indication that this type of turbine energy source will not be time efficient. If the energy required for IoT is too low; a few milli-watts, compared to its optimum capacity, as earlier discussed, then it will amount to waste of time and resources adopting this model. This is equally true for mini turbine PMM.

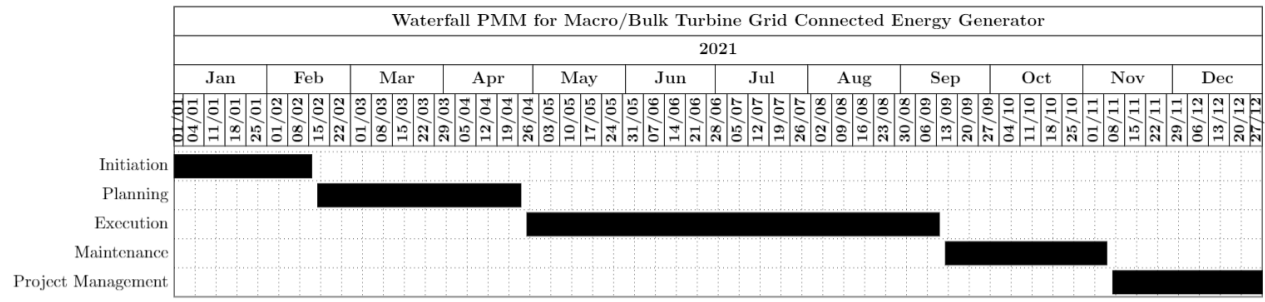

Figure 6. Waterfall PMM model of macro turbine grid-connected energy plant. 


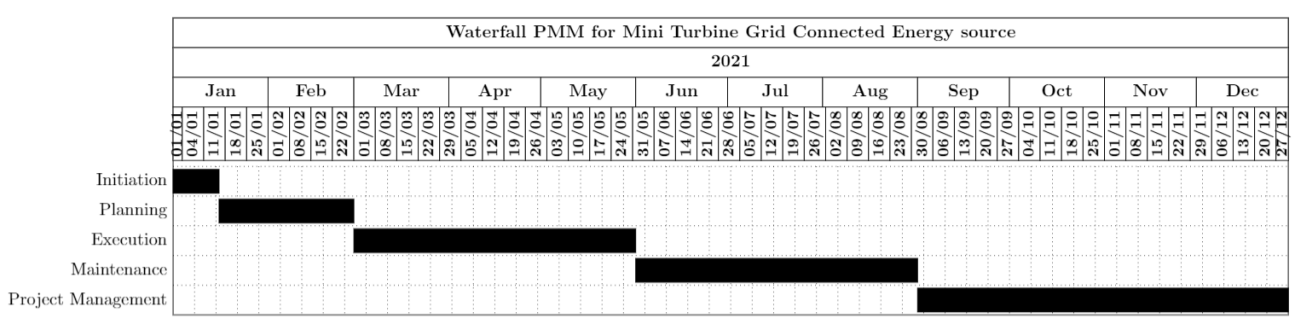

Figure 7. Waterfall PMM model of mini turbine grid-connected energy generator.

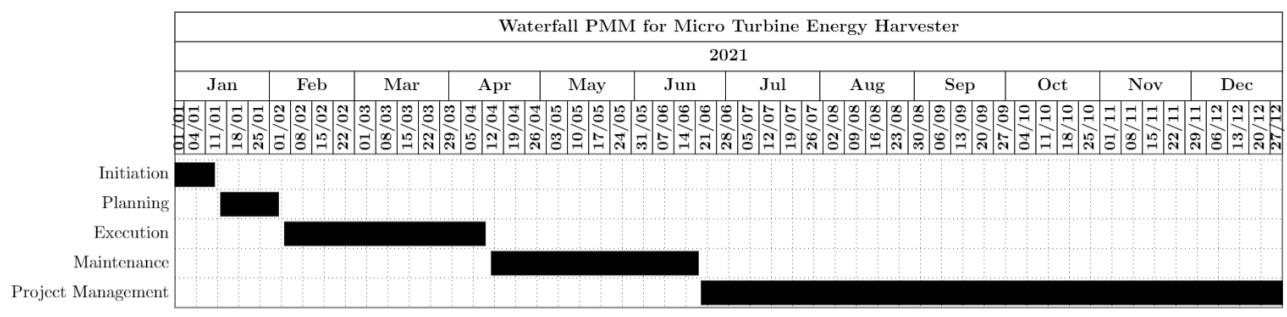

Figure 8. Waterfall PMM model of micro turbine energy harvester.

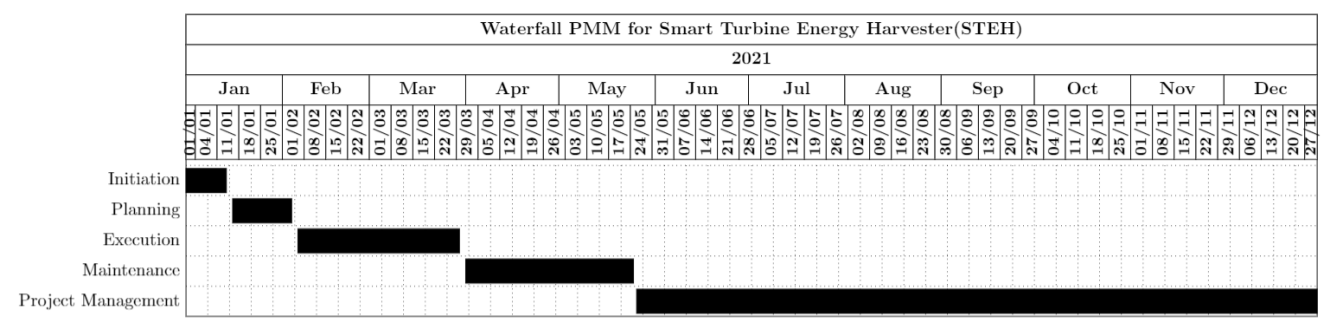

Figure 9. Waterfall PMM model of smart turbine energy harvester (STEH).

Table 1. Comparative analysis of PM process and requirement for different turbines.

\begin{tabular}{|c|c|c|c|c|c|}
\hline PM Processes & Requirements & $\begin{array}{l}\text { Macro/Bulk } \\
\text { Turbine }\end{array}$ & $\begin{array}{l}\text { Mini } \\
\text { Turbine }\end{array}$ & $\begin{array}{l}\text { Micro } \\
\text { Turbine } \\
\end{array}$ & STEH \\
\hline \multirow{8}{*}{ Initiation } & $\begin{array}{l}\text { Feasibility study / Energy } \\
\text { demand survey }\end{array}$ & ${ }^{*} \mathrm{R}$ & ${ }^{*} \mathrm{R}$ & ${ }^{*} \mathrm{R}$ & ${ }^{*} \mathrm{R}$ \\
\hline & Turbine farm site location determination & ${ }^{*} \mathrm{R}$ & ${ }^{*} \mathrm{R}$ & ${ }^{*} \mathrm{~N} / \mathrm{R}$ & ${ }^{*} \mathrm{~N} / \mathrm{R}$ \\
\hline & Land procurement & ${ }^{*} \mathrm{R}$ & ${ }^{*} \mathrm{R}$ & ${ }^{*} \mathrm{~N} / \mathrm{R}$ & ${ }^{*} \mathrm{~N} / \mathrm{R}$ \\
\hline & $\begin{array}{l}\text { Technical assessment of any } \\
\text { physical/viability constraint }\end{array}$ & ${ }^{*} \mathrm{R}$ & ${ }^{*} \mathrm{R}$ & ${ }^{*} \mathrm{~N} / \mathrm{R}$ & ${ }^{*} \mathrm{~N} / \mathrm{R}$ \\
\hline & $\begin{array}{l}\text { Initial assessment of wind resources } \\
\text { availability }\end{array}$ & ${ }^{*} \mathrm{R}$ & ${ }^{*} \mathrm{R}$ & ${ }^{*} \mathrm{R}$ & ${ }^{*} \mathrm{R}$ \\
\hline & $\begin{array}{l}\text { Initial assessment of project } \\
\text { costs/Return on Investment }\end{array}$ & ${ }^{*} \mathrm{R}$ & ${ }^{*} \mathrm{R}$ & ${ }^{*} \mathrm{R}$ & ${ }^{*} \mathrm{R}$ \\
\hline & Initial level of risk assessment & ${ }^{*} \mathrm{R}$ & ${ }^{*} \mathrm{R}$ & ${ }^{*} \mathrm{R}$ & ${ }^{*} \mathrm{~N} / \mathrm{R}$ \\
\hline & Project initiation documentation & ${ }^{*} \mathrm{R}$ & ${ }^{*} \mathrm{R}$ & ${ }^{*} \mathrm{R}$ & ${ }^{*} \mathrm{R}$ \\
\hline \multirow{4}{*}{ Planning } & Site preparation & ${ }^{*} \mathrm{R}$ & ${ }^{*} \mathrm{R}$ & ${ }^{*} \mathrm{~N} / \mathrm{R}$ & ${ }^{*} \mathrm{~N} / \mathrm{R}$ \\
\hline & Budgetary plan & ${ }^{*} \mathrm{R}$ & ${ }^{*} \mathrm{R}$ & ${ }^{*} \mathrm{R}$ & ${ }^{*} \mathrm{R}$ \\
\hline & $\begin{array}{l}\text { Ecological considerations (birds } \\
\text { and bats) }\end{array}$ & ${ }^{*} \mathrm{R}$ & ${ }^{*} \mathrm{R}$ & ${ }^{*} \mathrm{~N} / \mathrm{R}$ & ${ }^{*} \mathrm{~N} / \mathrm{R}$ \\
\hline & $\begin{array}{l}\text { Physical constraints (Communication } \\
\text { Links, power lines, water courses, etc.) }\end{array}$ & ${ }^{*} \mathrm{R}$ & ${ }^{*} \mathrm{R}$ & ${ }^{*} \mathrm{~N} / \mathrm{R}$ & ${ }^{*} \mathrm{~N} / \mathrm{R}$ \\
\hline
\end{tabular}


Table 1. Cont.

\begin{tabular}{llllll}
\hline \multirow{2}{*}{ PM Processes } & Requirements & $\begin{array}{l}\text { Macro/Bulk } \\
\text { Turbine }\end{array}$ & $\begin{array}{l}\text { Mini } \\
\text { Turbine }\end{array}$ & $\begin{array}{l}\text { Micro } \\
\text { Turbine }\end{array}$ & STEH \\
\hline \multirow{4}{*}{ Execution } & Energy harvesting & ${ }^{*} \mathrm{R}$ & ${ }^{*} \mathrm{R}$ & ${ }^{*} \mathrm{R}$ & ${ }^{*} \mathrm{R}$ \\
& Termination to the grid & ${ }^{*} \mathrm{R}$ & ${ }^{*} \mathrm{R}$ & ${ }^{*} \mathrm{~N} / \mathrm{R}$ & ${ }^{*} \mathrm{~N} / \mathrm{R}$ \\
& Load termination & ${ }^{*} \mathrm{R}$ & ${ }^{*} \mathrm{R}$ & ${ }^{*} \mathrm{R}$ & ${ }^{*} \mathrm{R}$ \\
& Metering & ${ }^{*} \mathrm{R}$ & ${ }^{*} \mathrm{R}$ & ${ }^{*} \mathrm{~N} / \mathrm{R}$ & ${ }^{*} \mathrm{~N} / \mathrm{R}$ \\
\hline \multirow{3}{*}{ Maintenance } & Storage system management & ${ }^{*} \mathrm{R}$ & ${ }^{*} \mathrm{R}$ & ${ }^{*} \mathrm{R}$ & ${ }^{*} \mathrm{~N} / \mathrm{R}$ \\
& Grid capacity management & ${ }^{*} \mathrm{R}$ & ${ }^{*} \mathrm{R}$ & ${ }^{*} \mathrm{~N} / \mathrm{R}$ & ${ }^{*} \mathrm{~N} / \mathrm{R}$ \\
& Energy optimization modelling & ${ }^{*} \mathrm{R}$ & ${ }^{*} \mathrm{R}$ & ${ }^{*} \mathrm{R}$ & ${ }^{*} \mathrm{~N} / \mathrm{R}$ \\
\hline \multirow{2}{*}{ Monitoring and control } & Noise Pollution & ${ }^{*} \mathrm{R}$ & ${ }^{*} \mathrm{R}$ & ${ }^{*} \mathrm{~N} / \mathrm{R}$ & ${ }^{*} \mathrm{~N} / \mathrm{R}$ \\
& Risk management control & ${ }^{*} \mathrm{R}$ & ${ }^{*} \mathrm{R}$ & ${ }^{*} \mathrm{~N} / \mathrm{R}$ & ${ }^{*} \mathrm{~N} / \mathrm{R}$ \\
\hline Project Management & End project and Signoff & ${ }^{*} \mathrm{R}$ & ${ }^{*} \mathrm{R}$ & ${ }^{*} \mathrm{R}$ & ${ }^{*} \mathrm{R}$ \\
\hline
\end{tabular}

\section{Results}

The waterfall PMM of the different categories of turbines grid-connected or without grid sources are as shown in Figures 6-9. The stages of project process are described by Gantt charts; which are usually adopted as one of the basic toolkits of waterfall PMM. These are used to describe the turbine grid or no-grid connected energy sources from initiation phase; to planning; to execution; up till the final stage of control and monitoring, which is simply put as Project Management in this study.

\subsection{Comparative Analysis of the Essential Requirements of Setting Up a Turbine Supplied Grid from Macro to Micro Using Waterfall Gantt Chart}

It is important to bear in mind that all turbine energy sources have their unique features while referring to magnitude, energy predictability, controllability, etc. Some of these features are analysed in Table 1, (where *R stands for 'Required', while *N/R stands for 'Not Required'). They are explained thus:

1. Magnitude, requirements and the resulting output based on the intended load capacity.

2. Energy predictability: this is a function of weather and the changing season of the year, relative to the geographical location of the site of the plant, among other atmospheric and environmental conditions;

3. Controllability: This is where the PM has to put in a lot of brainstorming and effort in order to arrive at a suitable forecast for the particular turbine energy required. Hence, much emphases are laid on execution of the project for the PMM of this study.

All conditions must be optimised thoroughly in order to arrive at the maximum power of the turbine harvester. In small harvesters, this is referred to as Maximum Power Point Tracking (MPPT). However, the detailed architecture of the turbine categories is not included in order not to lose focus on the objective of this study, which is the issue of Project Management categorisation of turbine-grid connected energy sources. This is as earlier shown in Figure 5 and Table 1. It is possible to move from A-to-B-to-C-to-D for macro turbine PMM; in Figure 5, or from A-to-C-to-D for mini turbine PMM; or one could connect directly from A-to-D, as it is with the cases of STEH and Micro Turbines.

Moreover, it is argued that these types of turbine energy sources may not be economical and time friendly in the situations where the energy required is for a few mill-watts; such as those for IoT devices or WSNs applications. Moreover, if supplying energy to the devices is required for immediate interventions in the face of emergencies, then scaling down from a macro-grid turbine to micro in order to obtain the little energy required for IoT and WSNs may not be as effective, rather it will amount to incurring more cost and time lagging in the face of responding to emergencies. 


\subsection{Comparative Analysis Using Waterfall PMM Requirements}

It is illustrated in Table 1 that one category of turbine requires more inputs and efforts than the other in initial preparation, planning, budget, risk management, man power, maintenance, etc.

It is stated in this study that macro turbine energy generation requires many of these necessities, hence, it will be a waste of resources to embark on such a project for the purpose of powering IoT or WSN nodes that require just a few milli-watts for their operation.

\section{Discussion}

Energy Harvesting $(\mathrm{EH})$, or energy scavenging is the process of deriving energy from ambient sources such as solar, thermal, wind, salinity gradients, and vibrations or kinetic energy; captured and stored for small, autonomous devices, such as those used in Internet of Things (IoT), Wireless Sensor Networks (WSN), and wearable electronics. This type of energy is renewable, and also act as alternative source of energy to the burning of fossil fuel, being able to sustain the ecological system to an appreciable level. It also answers the quest for more sources of energy to cumber the challenge of powering these autonomous devices, whose deployment is on the rise in recent time, and supplying energy to them is of major concern [41-43]. This aspect was presented in Section 1 of this paper, where it introduced this study stating the objectives of as the use of PMM to categorise and compare turbine energy sources from macro to micro in comparison to the use of STEH.

In Section 2, efforts were made to explain waterfall Project Management Methodology, and some studies from literature on turbine grid connected and non-grid energy sources.

Sections 3-5 buttress on the main objectives of this study. The use of smart turbine energy harvesters (STEH) to derive energy from wind and water as natural surrounding sources is discussed in this research. This process is assessed based on comparative analysis with the conventional means of obtaining energy from wind or water, using waterfall PMM, from the point of view of a Project Management.

There are different sizes of turbine grid capacity; classified as macro, mini, and micro in this study. This is achieved by considering the essential requirements adopted in setting up a turbine grid such as the equipment or facilities; as the case may be: the land purchase, construction (which involves site clearance), development cost, insurance, etc. All these factors put together are important components of Project Management Methodology (PMM) in this study, and they are determinants of the economic value and the Return on Investment (RI) of any turbine grid; either wind or water. Hence, in this study, for reasons of effectiveness, effort is geared towards how 'waterfall' PMM can be used to classify wind turbine grid connected energy into different categories from macro to micro. Additionally, we bear in mind the effect of trending digitisation which necessitates the massive deployment of autonomous devices for the purposes of smart city needs, and the resulting increase in energy demand for these devices. This brought about the need to scale down turbine technology the more in order to come to terms with such issues as comparing the economic category of turbine with respect to self-sustainability; ecology preservation; and most importantly the ubiquitous as well as long lasting requirements of renewable energy needed to power IoT and autonomous devices. Such are the features of the 'Smart Turbine Energy Harvester (STEH)' developed at the premises of Institute of Telecommunications, Aveiro University.

The comparative advantages of STEH are born out of the relieves presented over the conventional turbine harvesters in terms of their requirements discussed in Section 2.3, and as explained in Table 1. These are further itemised in the following points.

\section{Comparative Advantages of STEH}

The energy captured in this form is clean, ubiquitous, long lasting, and also sufficient to power the attached IoT sensors that are connected through LORAWAN. It is able to sustain the ecological system to an appreciable level with no carbon burning, in the process of IoT support for supply of sensory data to city planners for the purpose of environmental 
monitoring and automation. In this vein, this paper describes STEH as a more efficient means of energy support to smart city IoT sensors.

- Ecology friendliness and environmental sustainability:

The sustainable developmental goals of STEH as advantages over other categories of turbine energy sources are as illustrated in Figure 10. The energy harvested by STEH is clean, ubiquitous, long lasting, and also sufficient to power the attached IoT sensors for applications such as Internet of Medical Things (IoMT), Internet of Remote Things (IoRT), Internet of Mobile Things (IoMobT), and other sustainable goals of smart city, as shown in Figure 10.

- Battery-Less: There is a conscious effort to go green in sustainability issues relating to energy usage, also technology digitisation has began to have concerns for battery usage and disposal for reasons of cost of replacement; disposal; and toxicity to the ecology system [22,44]. Additionally, in most cases of reliability issues, IoT systems using batteries such as those of micro turbine harvester can pack up without warning, and that is not desirable in rescue missions; health monitoring, or in the face of emergencies, as shown in Figure 10. Therefore, STEH having all these conditions in consideration can be proposed to be preferable to a micro turbine harvester that uses battery.

- Cost Efficiency:

(i) STEH is cost saving in that it requires few items and off-the-counter components to set up a unit. The main structure of the model is an 18-blade turbine, which is a passive device in most Portuguese home chimney towers, but has gained a derived usage in this research. This is informed in the reason our SWDT-EH is also called 'Chimney Turbine Energy Harvester' (CTEH).

(ii) STEH is also cost saving for the reason of minimal number of man power requirement unlike macro and mini grid set ups that have need for large number of labour for different tasks as shown in Table 1. Although the team player can be repeatedly multiplied at several locations within the smart city.

(iii) There is no cost incurred for cabling and energy termination to the IoT nodes: unlike macro and mini turbine grids, that require high cost of cabling for transmission, distribution and termination to the loads, STEH is more of energy boxes, that has both the energy units and the IoT attached to the same structure, hence the cost of cabling is completely eradicated.

(iv) There is little or no energy wastage: there is usually special considerations for energy loss in the large turbine plants during transmission to the grid and distribution from grid to load centres. However, in the case of STEH, there are no such procedures hence no losses, since energy are being harvested and consume at same instance. This makes STEH has ubiquitous and self sustainability advantages.

(v) There is reduced cost of maintenance or no maintenance at all in the case of STEH as against the other categories of turbines. This is because once STEH are deployed either underwater or on house roof tops, they are required to be long lasting with long lifespan of the IoT node.

(vi) There is complete eradication of cost of battery procurement and disposal in STEH. This is because the IoT attached is constantly taking environmental data, hence since energy is also continuously harvested from the wind or water as the case may be, once it arrives, there's a little hold by the scavenger in the power management circuit, then it is released for onward supply to the IoT.

- Time Saving Capability:

(i) The period of setting up is short as shown in Figure 9, compared to other categories, STEH is observed to arrive at the execution stage faster in about 6 weeks, and it also get to deployment stage earlier than others, unlike the turbine plants that require land procurement, permission to be obtained, and careful consideration for many factors and feasibility studies as shown in Table 1. 
(ii) Short time is required for termination to the load, and STEH is always present with the load, hence it is time saving in the situation of emergencies or rescue operations, instead of waiting on calling grid protocols like the bulk turbine.

(iii) There is no time wastage for battery replacement or any inactivity of system due to breakdown as a result of battery pack up.

- Man power: there is reduced man power usage in this project, a maximum of 2 or 3 personnel are sufficient to make a team, this brings about a reduction in cost of manpower. However, it has a social economic advantage in that several unit of this model can be deployed in the smart city at different locations at the same time with individual IoT nodes, hence hundreds of team players could be engaged in fabricating this same model at the same time within the smart city.

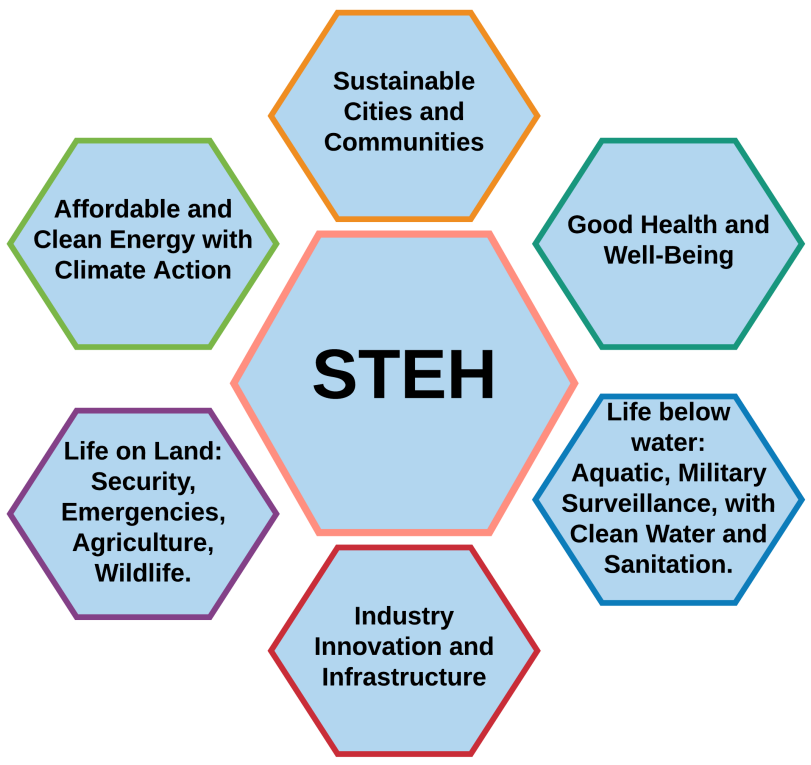

STEH Sustainable Goals

Figure 10. Sustainable development goals of STEH.

Meanwhile, the choice of dynamo attached to STEH; which is as essential part of the set-up because turbines are not stand-alone harvesters [21], can pose a serious disadvantage if not carefully selected. This was evident in the initial choice of bicycle dynamo which was too weighty for the turbine to spin. However, if all conditions are suitably satisfied, STEH will produce energy delivery that is sufficient for the instant requirement of IoT and other autonomous devices. There will also be savings on battery acquisition and disposal.

\section{Conclusions}

Waterfall/Staircase PMM, was used in this study to make effective comparisons and in classifying wind turbine grid connected energy into different categories from macro to micro. This paper presents the comparative study between scaling down of turbine grids from macro to micro, to the economic impact of setting up Smart Turbine Energy Harvesting (STEH), from the point of view of Project Management (PM). This is in process of obtaining the few milli-Watt needed to power IoT and autonomous devices, in order to come to terms with such issues as sustainability, ecology preservation, and most importantly the ubiquitous and long lasting requirements of renewable energy needed to power autonomous devices. Such are the features of the 'Smart Turbine Energy Harvester (STEH)' developed at the premises of Institute of Telecommunications, Aveiro University, Portugal. This study concludes by proposing that the use of STEH which is an on-site energy harvesting that is renewable and self-sustaining; ubiquitous and long lasting is preferable over the other categories of turbine grid system, since it is economical and time saving with little or no physical risk attached, there is no risk in investment, hence 
the RI is considered favourable. This is a desire in the Project Management process for sustainability of digitised technology. In the era of digitised technology, the energy supply to autonomous devices could be realised directly from the table-top STEH described in this article, rather than investing so much in the other categories of turbines to meet the same need. Additionally, there is preservation of ecology system as well as social-life impact in adopting the methods of PPM proposed for STEH in this study. Smart city automation has brought about the paradigm of sensory data, and the need for unending scavenging for energy to sustain the connected devices will continue to be a research area of interest as long as digitised technology keeps evolving.

Author Contributions: Conceptualization, A.E.A.-P.; funding acquisition, N.B.C.; methodology, R.C.M.; supervision, F.S.P. and N.B.C.; validation, R.C.M.; writing-original draft, A.E.A.-P.; writingreview and editing, A.E.A.-P. and N.B.C. All authors have read and agreed to the published version of the manuscript.

Funding: This work is funded by FCT/MCTES through national funds, and co-funded by EU funds under the project UIDB/50008/2020-UIDP/50008/2020.

Institutional Review Board Statement: Not applicable.

Informed Consent Statement: Not applicable.

Data Availability Statement: Not applicable.

Acknowledgments: Tertiary Education Trust Fund (TETFUND), Nigeria, The Federal Polytechnic Ile-Oluji, Nigeria.

Conflicts of Interest: The authors declare that there is no conflict of interest.

Abbreviations
The following abbreviations are used in this manuscript
$\begin{array}{ll}\text { STEH } & \text { Smart Turbine Energy Harvester } \\ \text { PM } & \text { Project Management } \\ \text { IoT } & \text { Internet of Things } \\ \text { PMM } & \text { Project Management Methodology } \\ \text { EH } & \text { Energy Harvesting } \\ \text { RI } & \text { Return on Investment } \\ \text { GHGE } & \text { GreenHouse Gas Emission } \\ \text { WSN } & \text { Wireless Sensor Network } \\ \text { RFID } & \text { Radiofrequency Identification } \\ \text { SWDT-EH } & \text { Smart Wind Turbine Energy Harvester } \\ \text { SWRT-EH } & \text { Smart Water Turbine Energy Harvester } \\ \text { SHM } & \text { Structural Health Monitoring }\end{array}$

\section{References}

1. Nair, K.; Kulkarni, J.; Warde, M.; Dave, Z.; Rawalgaonkar, V.; Gore, G.; Joshi, J. Optimizing power consumption in iot based Wireless Sensor Networks using Bluetooth Low Energy. In Proceedings of the 2015 International Conference on Green Computing and Internet of Things (ICGCIoT), Greater Noida, India, 8-10 October 2015; pp. 589-593.

2. Nandi, M.; Sarkar, S. Coverage Problem of sensor network in Continuous Region. In Proceedings of the IEEE In 2019 International Conference on Ubiquitous and Emerging Concepts on Sensors and Transducers (UEMCOS), Kolkata, India, 25-27 April 2019; Volume 1, pp. 1-8.

3. Behrouzi, F.; Nakisa, M.; Maimun, A.; Ahmed, Y.M. Global renewable energy and its potential in Malaysia: A review of Hydrokinetic turbine technology. Renew. Sustain. Energy Rev. 2016, 62, 1270-1281. [CrossRef]

4. Balat, M. A review of modern wind turbine technology. Energy Sour. 2009, 31, 1561-1572. [CrossRef]

5. Lyu, X.; Jia, Y.; Xu, Z. A novel control strategy for wind farm active power regulation considering wake interaction. IEEE Trans. Sustain. Energy 2019, 11, 618-628. [CrossRef]

6. Cammarano, A.; Petrioli, C.; Spenza, D. Online energy harvesting prediction in environmentally powered Wireless Sensor Networks. IEEE Sens. J. 2016, 16, 6793-6804. [CrossRef] 
7. Munteanu, I.; Bacha, S.; Bratcu, A.I.; Guiraud, J.; Roye, D. Energy-reliability optimization of wind energy conversion systems by sliding mode control. IEEE Trans. Energy Conv. 2008, 23, 975-985. [CrossRef]

8. Jung, H.J.; Lee, S.W.; Jang, D.D. Feasibility study on a new energy harvesting electromagnetic device using aerodynamic instability. IEEE Trans. Magn. 2009, 45, 4376-4379. [CrossRef]

9. Carlin, P.W.; Laxson, A.S.; Muljadi, E.B. The history and state of the art of variable-speed wind turbine technolog. Wind Energy Int. J. Progress Appl. Wind Power Conv. Technol. 2003, 6, 129-159.

10. Clausen, P.D.; Wood, D.H. Recent advances in small wind turbine technology. Wind Eng. 2000, 24, 189-201. [CrossRef]

11. Chin, C.; Spowage, A.; Yap, E. Project Management methodologies: A comparative analysis. J. Adv. Perform. Inf. Value 2012, 4, 106-118. [CrossRef]

12. Van Casteren, W. The Waterfall Model and the agile Methodologies: A comparison by project characteristics. Res. Gate 2017, 2, 1-6.

13. Thesing, T.; Feldmann, C.; Burchardt, M. Agile versus Waterfall Project Management: Decision Model for Selecting the Appropriate Approach to a Project. Procedia Comput. Sci. 2021, 181, 746-756. [CrossRef]

14. Kaldellis, J.K. The contribution of small hydro power stations to the electricity generation in Greece: Technical and economic considerations. Energy Policy 2007, 35, 2187-2196. [CrossRef]

15. Piano, S.L.; Mayumi, K. Toward an integrated assessment of the performance of photovoltaic power stations for electricity generation. Appl. Energy 2017, 186, 167-174. [CrossRef]

16. Danlami, B.A.; Eunice, A.A.; Jimoh, Y.A. Simulation of a Hybrid Power Generation System (A Case Study of Oke Eda, Akure, Ondo State, Nigeria). Am. J. Modern Energy 2019, 5, 23-34. [CrossRef]

17. Granovetter, M.; McGuire, P. The making of an industry: Electricity in the United States. Sociol. Rev. 1998, 46, 147-173. [CrossRef]

18. Kaldellis, J.K.; Zafirakis, D. Optimum energy storage techniques for the improvement of renewable energy sources-based electricity generation economic efficiency. Energy 2007, 32, 2295-2305. [CrossRef]

19. Hirst, E.; Kirby, B. Electric-Power Ancillary Services; Oak Ridge National Laboratory: Oak Ridge, TN, USA, 1996; pp. 1-48.

20. Hebra, A. The reality of generating and transmitting ultrahigh voltage power, Part 1. IEEE Instrum. Meas. Mag. 2012, 15, 26-31. [CrossRef]

21. Akin-Ponnle, A.E.; Carvalho, N.B. Energy Harvesting Mechanisms in a Smart City-A Review. Smart Cities 2021, 4, 476-498. [CrossRef]

22. Espinosa, D.C.R.; Bernardes, A.M.; Tenório, J.A.S. Brazilian policy on battery disposal and its practical effects on battery recycling. J. Power Sour. 2004, 137, 134-139. [CrossRef]

23. Nehrir, M.H.; Wang, C.; Strunz, K.; Aki, H.; Ramakumar, R.; Bing, J.; Miao, Z.; Salameh, Z. A review of hybrid renewable/alternative energy systems for electric power generation: Configurations, control, and applications. IEEE Trans. Sustain. Energy 2011, 2, 392-403. [CrossRef]

24. Aderogba, K.A. Global warming and challenges of floods in Lagos metropolis, Nigeria. Acad. Res. Int. $2012,2,448-468$.

25. Qazi, A.; Hussain, F.; Rahim, N.A.; Hardaker, G.; Alghazzawi, D.; Shaban, K.; Haruna, K. Towards sustainable energy: A systematic review of renewable energy sources, technologies, and public opinions. IEEE Access 2019, 7, 63837-63851. [CrossRef]

26. Hammons, T.J.; Boyer, J.C.; Conners, S.R.; Davies, M.; Ellis, M.; Fraser, M.; Holt, E.A.; Markard, J. Renewable energy alternatives for developed countries. IEEE Trans. Energy Conv. 2000, 15, 481-493. [CrossRef]

27. Perrier, Q.; Guivarch, C.; Boucher, O. Diversity of greenhouse gas emission drivers across European countries since the 2008 crisis. Clim. Policy 2019, 19, 1067-1087. [CrossRef]

28. Bell, T.E.; Thayer, T.A. Software requirements: Are they really a problem? In Proceedings of the 2nd International Conference on Software Engineering, San Francisco, CA, USA, 13-15 October 1976; pp. 61-68.

29. Adhikari, J.; Panda, S.K. Overview of high altitude wind energy harvesting system. In Proceedings of the IEEE 20135 th International Conference on Power Electronics Systems and Applications (PESA), Hong Kong, China, 11-13 December 2013; pp. 1-8.

30. Muljadi, E.; Pasupulati, S.; Ellis, A.; Kosterov, D. Method of equivalencing for a large wind power plant with multiple turbine representation. In Proceedings of the 2008 IEEE Power and Energy Society General Meeting-Conversion and Delivery of Electrical Energy in the 21st Century, Pittsburgh, PA, USA, 20-24 July 2008; pp. 1-9.

31. Ancona, D.; McVeigh, J. Wind turbine-materials and manufacturing fact sheet. Princet. Energy Resour. Int. LLC 2001, 19, 1-8.

32. Camm, E.H.; Behnke, M.R.; Bolado, O.; Bollen, M.; Bradt, M.; Brooks, C.; Dilling, W.; Edds, M.; Hejdak, W.J.; Walling, R.; et al. Characteristics of wind turbine generators for wind power plants. In Proceedings of the 2009 IEEE Power and Energy Society General Meeting, Calgary, AB, Canada, 26-30 July 2009; pp. 1-5.

33. Kekezoğlu, B.; Tanrı̈̈ven, M.; Erduman, A. A new wind turbine concept: Design and implementation. Acta Polytech. Hungar. 2015, 12, 3 .

34. Ciulla, G.; Franzitta, V.; Lo Brano, V.; Viola, A.; Trapanese, M. Mini wind plant to power telecommunication systems: A case study in sicily. Adv. Mater. Res. 2013, 622, 1078-1083. [CrossRef]

35. Lapointe, C.; Gopalan, H. Numerical investigation of mini wind turbines near highways. J. Sol. Energy Eng. 2016, 138, 024503. [CrossRef]

36. Carli, D.; Brunelli, D.; Bertozzi, D.; Benini, L. A high-efficiency wind-flow energy harvester using micro turbine. In Proceedings of the SPEEDAM 2010, Pisa, Italy, 14-16 June 2010; pp. 778-783. 
37. Hamdan, A.; Mustapha, F.; Ahmad, K.A.; Rafie, A.M. A review on the micro energy harvester in Structural Health Monitoring (SHM) of biocomposite material for Vertical Axis Wind Turbine (VAWT) system: A Malaysia perspective. Renew. Sustain. Energy Rev. 2014, 35, 23-30. [CrossRef]

38. Bhutta, M.M.A.; Hayat, N.; Farooq, A.U.; Ali, Z.; Jamil, S.R.; Hussain, Z. Vertical axis wind turbine-A review of various configurations and design techniques. Renew. Sustain. Energy Rev. 2012, 16, 1926-1939. [CrossRef]

39. Templin, R.J. Aerodynamic performance theory for the NRC vertical-axis wind turbine. NASA STI/RECON Tech. Rep. 1974, 76, 16618.

40. Ro, K.D. Experiments on Hydrodynamic Performance of Weis-Fogh-Type Water Turbine. Trans. Canad. Soc. Mech. Eng. 2014, 38, 405-415. [CrossRef]

41. Shirvanimoghaddam, M.; Shirvanimoghaddam, K.; Abolhasani, M.M.; Farhangi, M.; Barsari, V.Z.; Liu, H.; Dohler, M.; Naebe, M. Towards a Green and Self-Powered Internet of Things Using Piezoelectric Energy Harvesting. IEEE Access 2019, 7, 94533-94556. [CrossRef]

42. Khajenasiri, I.; Estebsari, A.; Verhelst, M.; Gielen, G. A review on Internet of Things solutions for intelligent energy control in buildings for smart city applications. Energy Procedia 2017, 111, 770-779. [CrossRef]

43. Golpîra, H.; Bahramara, S. Internet-of-things-based optimal smart city energy management considering shiftable loads and energy storage. J. Clean. Prod. 2020, 264, 121620. [CrossRef]

44. Kowey, B.N. An Example of Planning for Sustainable Production: The Dry-Cell Battery Problem. Doctoral Dissertation, University of British Columbia, Vancouver, BC, Canada, 1990. 